\title{
Extraction and Properties of Acid-Soluble Collagen and Pepsin-Soluble Collagen from Silver Carp (Hypophthalmichthys molitrix) Scales: Prerequisite Information for Fishery Processing Waste Reuse
}

\author{
Jiacheng Wu', Lili Kong ${ }^{1}$, Jinwei Zhang ${ }^{1}$, Wuyong Chen ${ }^{1,2 *}$ \\ ${ }^{1}$ National Engineering Laboratory for Clean Technology of Leather Manufacture, Sichuan University, Chengdu, China \\ ${ }^{2}$ Key Laboratory of Leather Chemistry and Engineering of Ministry of Education, Sichuan University, Chengdu, China
}

Received: 24 May 2018

Accepted: 24 July 2018

\begin{abstract}
As a waste of the fish processing industry, scales cause the disposal of large amounts of solid waste into the environment. How to turn such waste into a useful product is an important issue. In this study, acid-soluble collagen (ASC) and pepsin-soluble collagen (PSC) were extracted from silver carp (Hypophthalmichthys molitrix) scales using a new acid-enzyme combined method. The results showed that the extraction yields of ASC and PSC were $5.09 \%$ and $12.06 \%$, respectively. Then amino acid analysis, sodium dodecyl sulfate polyacrylamide gel electrophoresis (SDS-PAGE), Fourier transform infrared spectroscopy (FT-IR), circular dichroism (CD) and ultra-sensitive differential scanning calorimetry (US-DSC) were used to study their composition, properties and structure. Amino acid analysis indicated that ASC and PSC were type I collagens with 34\% glycine and $20 \%$ imino acid (Pro and Hyp). The results of SDS-PAGE and FT-IR analysis showed that ASC and PSC were similar to those of the standard type I collagen. CD indicated that the triple helical structure of both ASC and PSC were still retained. And the transition from triple helix to random coil of ASC and PSC were $34.26^{\circ} \mathrm{C}$ and $34.47^{\circ} \mathrm{C}$, respectively. For the first time, the collagen yields of silver carp scales were calculated. Meanwhile, their composition, properties and structure were characterized. These results may offer theoretical support for the development of silver carp scales related to reusing technology to control waste.
\end{abstract}

Keywords: silver carp; fish scales; collagen; extraction; reuse

*e-mail: wuyong.chen@163.com 


\section{Introduction}

With its vast expanse of water, China has abundant aquatic resources. According to the statistical data, the output of freshwater fish was more than 2600 million tons in 2013, and the annual growth rate was not less than $5 \%$. Due to the increasing demand for fish products diversification, the processing industry is going to be prosperous. However, fish processing generates a large amount of by-products, including skin, bone, scales, viscera and heads, which are about $50-70 \%$ of the original raw materials [1-2]. These wastes are rich in protein, minerals, lipids, trace elements and vitamins. Therefore, it will not only waste valuable resources, but also cause environmental pollution if there is no effective treatment.

In recent years, many countries have banned the use of bovine raw materials for the production of food or medicine because of the probability of disease transmission from the current sources such as transmissible spongiform encephalopathy (TSE), bovine spongiform encephalopathy (BSE) and foot-and-mouth disease (FMD) [3-4]. Moreover, due to religious beliefs, Muslims refuse to use terrestrial animal raw materials to produce high value-added products, so that the products obtained from the terrestrial animals gradually turn to be produced by marine organisms [5]. Therefore, research on the comprehensive utilization of the waste generated from fish processing is imperative. And reuse may lower costs, increase the product nutritional value and reduce the waste emissions and environmental pollution.

Studies have shown that fish scales contain a large quantity of protein (about $70 \%$ ), and consist mainly of keratin and collagen, which is considered a valuable resource with a strong biological function [6]. So making use of the scales is a promising way to produce value-added products as well as protect the environment. Currently, some research has been conducted on the extraction of collagen from freshwater fish scales. Duan et al. isolated collagens by acetic acid from skin, scales and bone of carp (Cyprinus carpio), and further studied its molecular weight and thermal denaturation temperature [7]. Li et al. reported the extraction of collagen from grass carp (Ctenopharyngodon idellus) scales by pepsin, and characterized the molecular weight, amino acid composition and triple helix conformation of collagen [8]. Mahboob et al. prepared the collagen from the scales of Catla catla and Cirrhinus mrigala, and described the molecular weight, amino acid composition, solubility and triple helix conformation [9]. Also, corresponding successful research in the food industry has been turned into commercial production, such as the tablets and canned foods containing collagen and apatite.

As shown by the statistics, silver carp is one of the "four major cultured fish species" along with black carp, grass carp and bighead carp grown in China [10]. However, few have been concerned with the extraction and properties of collagen from silver carp (Hypophthalmichthys molitrix) scales. Although acidsoluble collagen (ASC) and pepsin-soluble collagen (PSC) was isolated from silver carp scales [11], the yield of collagen was low (3.18\%) and the systematic study on the extraction and properties of ASC and PSC from silver carp scales has not been carried out so far. In this research, the ASC and PSC from silver carp scales have been extracted with a new method combined with acid and enzyme. Then the extracted collagen was characterized and compared systematically between the ASC and PSC by amino acid analyzer, SDS-PAGE, FT-IR, CD and US-DSC. The results may be useful in terms of the management of natural wastes or ecological problems.

\section{Material and Methods}

\section{Materials}

Fish scales were collected by hand from silver carp purchased from a local fish market in China. Pepsin (25000 U/mg) was purchased from Novozymes. All other chemicals were commercially available and of analytical grade.

\section{Methods}

\section{Proximate Composition}

A small portion of the silver carp scales was removed from the fish to determine the proximate composition. Moisture, crude protein, crude fat, ash and hydroxyproline contents of the scales were determined according to the method of AOAC [12].

\section{Pretreatment of Fish Scales}

Silver carp scales were washed with distilled water until there were no suspended solids, then lyophilized by a vacuum freeze drier (LGJ-10, Beijing Four-ring Science Instrument Plant Co. Ltd, China) and cut into about $2 \times 2 \mathrm{~mm}$. Small pieces of fish scales were suspended in $0.1 \mathrm{M} \mathrm{NaOH}$ for $24 \mathrm{~h}$ at a ratio of 1:20 $(w / v)$ with continuous stirring. The treated scales were washed with distilled water to a $\mathrm{pH}$ of about 7 , and then suspended in $0.6 \mathrm{M} \mathrm{HCl}$ for $1 \mathrm{~h}$ at a ratio of 1:20 (w/v) with continuous stirring. The two steps were to remove non-collagen protein, pigment and minerals [13-14]. All procedures were carried out at $4^{\circ} \mathrm{C}$.

\section{Isolation of Collagen from Fish Scales}

The pretreated scales were extracted with $0.5 \mathrm{M}$ acetic acid at a ratio of $1: 20(\mathrm{w} / \mathrm{v})$ for $24 \mathrm{~h}$ at $4^{\circ} \mathrm{C}$. The solution was filtered and centrifuged at $8,000 \mathrm{rpm}$ for $20 \mathrm{~min}$. The residue was extracted again as above. Then the supernatant of the two extracts was salted-out by 
adding the sodium chloride until solution concentration was $2 \mathrm{M}$ and solubilized by $0.5 \mathrm{M}$ acetic acid for two times. The solution was dialyzed $(8000 \mathrm{kDa})$ against 0.5 $\mathrm{M}$ acetic acid and distilled water, respectively [7]. And the resulted solution was lyophilized to get acid-soluble collagen (ASC).

The residue obtained from above was extracted in $0.5 \mathrm{M}$ acetic acid containing some pepsin at $4^{\circ} \mathrm{C}$. The solution was filtered and centrifuged at $8,000 \mathrm{rpm}$ for $20 \mathrm{~min}$. Then the supernatant was salted-out and solubilized twice. The solution was dialyzed against $0.5 \mathrm{M}$ acetic acid and distilled water respectively. And the resulting solution was lyophilized to get pepsinsoluble collagen (PSC). In order to optimize the experimental conditions, the single factor experiment was conducted to investigate the different effects of enzyme amounts (extraction time, 48h; solid-liquid ratio, 1:20), extraction time (enzyme, 3\%; solidliquid ratio, 1:20), and solid-liquid ratio (enzyme, 3\%; extraction time, $48 \mathrm{~h}$ ) on the extraction rate of PSC. After that, an orthogonal experiment was performed with the established parameters in order to obtain a suitable enzymatic extraction process.

\section{SDS-Polyacrylamide Gelelectrophoresis (SDS-PAGE)}

SDS-PAGE was conducted using the discontinuous Tris- $\mathrm{HCl}$ buffer system, with $10 \%$ separating gel and 5\% stacking gel. ASC and PSC were dissolved in $0.5 \mathrm{M}$ acetic acid to obtain a final concentration of $0.05 \mathrm{mg} / \mathrm{mL}$ approximately, and next the solutions were mixed at a ratio of $1: 1(\mathrm{v} / \mathrm{v})$ with the sample buffer $(0.0625 \mathrm{M}$ Tris- $\mathrm{HCl}, \mathrm{pH} 6.8$, containing $2.3 \%$ SDS, $10 \%$ glycerol and $5 \%$ mercaptoethanol), then the mixed solutions were boiled for $8 \mathrm{~min}$. The electrophoresis was performed by an electrophoresis instrument (Min-PROTENIN3, Bio-Rad Laboratories, Inc. USA) at a constant current of $60 \mathrm{~V}$ through the stacking gel and $120 \mathrm{~V}$ through the separating gel. After electrophoresis, the gel was visualized by $0.25 \%$ Coomassie Brilliant Blue R-250 for $2 \mathrm{~h}$ and destained in 5\% methanol and $7.5 \%$ acetic acid, and then analyzed by a gel imaging analysis system (BIO-RAD Gel Doc XR +, USA). High molecular weight markers (Sigma Chemical Co., USA) were used to estimate the molecular weight of collagen.

\section{Amino Acid Analysis}

The ASC and PSC were digested in $6 \mathrm{M}$ hydrochloric acid at $110^{\circ} \mathrm{C}$ for $24 \mathrm{~h}$ in the absence of oxygen. The solutions were filtered and diluted. An aliquot of $0.1 \mathrm{~mL}$ was applied to an amino acid analyzer (L-8900, Hitach i Limited, Japan).

\section{FT-IR Spectroscopy}

FT-IR spectra were measured by attenuated total reflection Fourier transform infrared spectroscopy
(ATR-FTIR) (Nicolet iS10, Thermo Fisher Scientific Inc. USA). $2 \mathrm{mg}$ of lyophilized ASC and PSC were ground with $\mathrm{KBr}(1: 100)$, respectively, and then the mixture was pressed into disks for spectrum recording. The spectra in the range of 500-4000 $\mathrm{cm}^{-1}$ with automatic signal gain were collected in 64 scans at a resolution of $4 \mathrm{~cm}^{-1}$ and rationed against a background spectrum recorded from the clean empty cell at $25^{\circ} \mathrm{C}$ [15].

\section{Circular Dichroism (CD) Spectroscopy and Ultra-Sensitive Differential Scanning Calorimetry (US-DSC)}

The ASC and PSC were dissolved in $0.05 \mathrm{M}$ acetic acid in order to obtain a final concentration of $0.05 \mathrm{mg} / \mathrm{ml}$, and $0.05 \mathrm{M} \mathrm{HAC}$ was as a control. For $\mathrm{CD}$ spectroscopy, the solutions were measured by $\mathrm{CD}$ spectrometer (J-810CD, Jasco Corporation., Japan) from 190 to $260 \mathrm{~nm}$ at a scan rate of $100 \mathrm{~nm} / \mathrm{min}$ with an interval of $0.5 \mathrm{~nm}$. For US-DSC analysis, the transition temperature of the samples was analyzed by US-DSC (MicroCal VP-DSC, General Electric Company, USA) scanning over the range of $15-50^{\circ} \mathrm{C}$ with the heating rate at $1^{\circ} \mathrm{C} / \mathrm{min}$.

\section{Results and Discussion}

\section{Composition of Silver Carp Scales}

Analyses shows that silver carp scales contain $16.71 \%$ moisture, $31.68 \%$ ash, $48.08 \%$ protein, $0.77 \%$ fat and $3.35 \%$ hydroxyproline on a dry weight basis. Obviously, the scales are mainly composed of protein and ash. Hydroxyproline is a characteristic amino acid of collagen, and therefore the approximate content of collagen in the scales can be calculated from the hydroxyproline content, and the conversion factor for aquatic animals is usually 11.1 [16]. As the hydroxyproline content is as high as $3.35 \%$, the content of collagen in the scales is approximately $37.19 \%$, accounting for $77.34 \%$ of the protein. So it shows that silver carp scales are good material for reusing the collagen.

\section{Extraction Yield}

The salt and Schiff bonds $(-\mathrm{C}=\mathrm{N}-)$ between the collagen molecules can be destroyed under acidic conditions. In this way, the tight structure of the collagen becomes looser and facilitates the extraction of ASC. However, excessively high concentrations of acid might result in collagen degradation and destroy its natural structure. Therefore, a smaller concentration of acetic acid $(0.5 \mathrm{M})$ was used in this work. The extraction yield of ASC was $5.09 \%$ on a dry-weight basis. Since the collagen content in the scales is approximately $37.19 \%$, it can be deduced that ASC accounts for approximately $13.69 \%$ of the total amount of the collagen. So, there is 
still a large amount of collagen existing in the scales after acid extraction. In order to increase the collagen yield, it is necessary to use the enzymatic method for further extraction.

With numbers of covalent cross-links formed between the molecules, collagen structure is very stable and generally insoluble in water, dilute acid or alkali, neutral salt solution and common organic solvents. However, studies have shown that there are no repeated Gly-X-Y amino acid sequences formed at the C-terminus
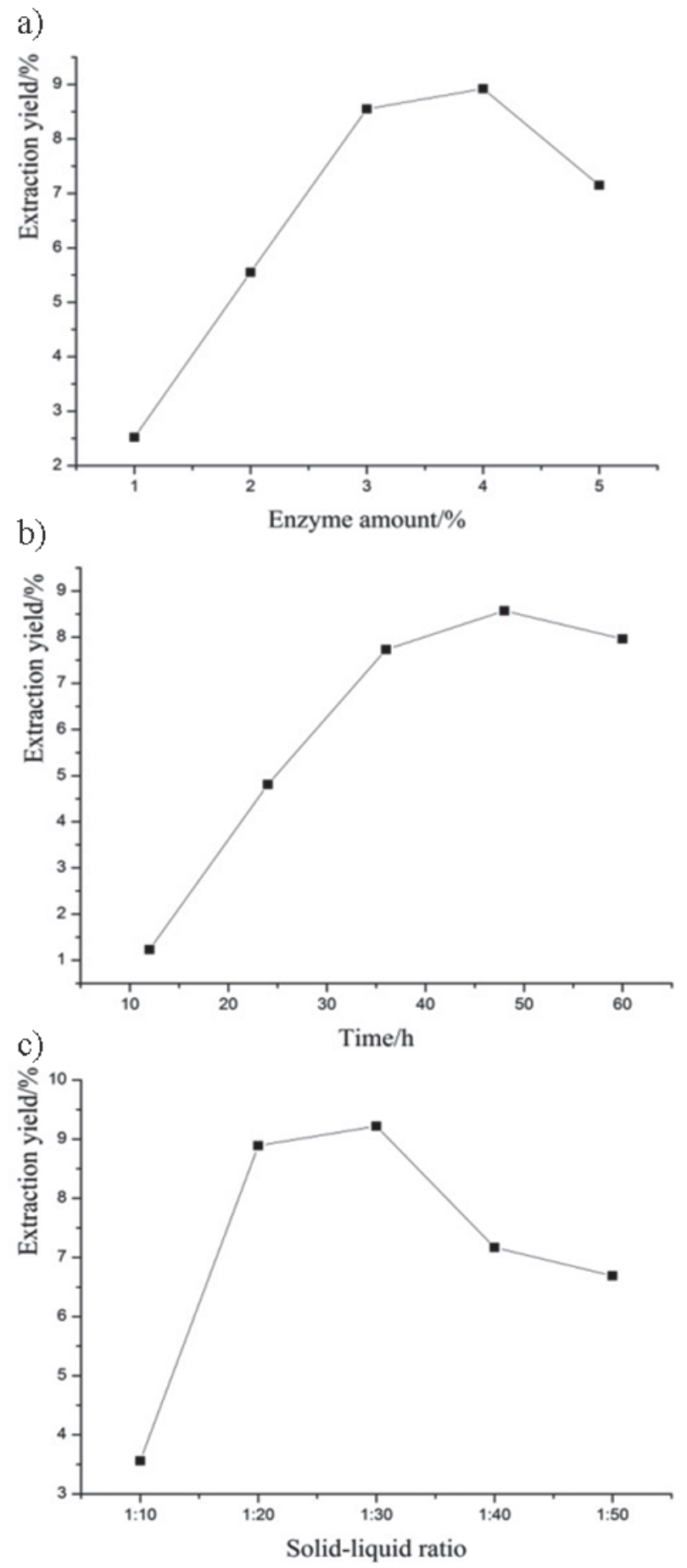

Fig. 1. Effect of enzyme amount a), extraction time b) and solidliquid ratio c) on the yield of pepsin-soluble collagen.
Table 1. Orthogonal test results of collagen extraction using pepsin.

\begin{tabular}{|c|c|c|c|c|}
\hline Number & A (\%) & B (h) & C & Extraction rate (\%) \\
\hline 1 & 3.5 & 36 & $1: 20$ & 10.97 \\
\hline 2 & 3.5 & 48 & $1: 25$ & 9.93 \\
\hline 3 & 3.5 & 60 & $1: 30$ & 8.77 \\
\hline 4 & 4.0 & 36 & $1: 25$ & 9.49 \\
\hline 5 & 4.0 & 48 & $1: 30$ & 9.20 \\
\hline 6 & 4.0 & 60 & $1: 20$ & 11.03 \\
\hline 7 & 4.5 & 36 & $1: 30$ & 9.80 \\
\hline 8 & 4.5 & 48 & $1: 20$ & 7.66 \\
\hline 9 & 4.5 & 60 & $1: 25$ & 10.97 \\
\hline K1 & 29.67 & 30.26 & 29.66 & \\
\hline K2 & 29.72 & 26.79 & 30.39 & \\
\hline K3 & 28.43 & 30.77 & 27.77 & \\
\hline k1 & 9.89 & 10.09 & 9.89 & \\
\hline k2 & 9.91 & 8.93 & 10.13 & \\
\hline k3 & 9.48 & 10.26 & 9.26 & \\
\hline R & 0.43 & 1.33 & 0.87 & \\
\hline & & & & \\
\hline
\end{tabular}

and N-terminus of the peptide chain, showing a nonhelix region [17]. Pepsin is able to act on such a nonhelical region and destroy the covalent and non-covalent bonds that stabilize the collagen structure, thereby promoting collagen dissolution. Hence, the pepsin can be used for collagen extraction from the scales [18].

The extraction yields of PSC first rise and then fall with the increasing enzyme amount, probably because the large use of pepsin results in the hydrolysis of partial collagen, so the amount of pepsin is appropriate for $4 \%$ as shown in Fig. 1a). During $48 \mathrm{~h}$ extraction there is a maximum yield of PSC (Fig. 1b). It can be explained by the acid or enzyme causing some collagen hydrolysis when the extraction time is longer, and then the produced smaller fragments of the peptide chain is easy to lose during the dialysis process, thereby resulting in a decrease in the amount of collagen. The extraction rate increases with the solid-liquid ratio at a certain enzyme amount and extraction time, and reaches the maximum when the solid-liquid ratio is 1:30, perhaps due to the fact that a low-enzyme concentration exists in the high solid-liquid ratio, resulting in a decrease in the extraction rate (Fig. 1c). Therefore, 1:30 is selected as the appropriate solid-liquid ratio.

According to the initially determined parameters, the orthogonal experiment was conducted with enzyme amounts (A) at 3.5, 4, 4.5\%, extraction time; (B) for 36, 48, $60 \mathrm{~h}$ and solid-liquid ratio; and (C) of $1: 20,1: 25,1: 30$ (Table 2). It can be seen from the range analysis that the degree of the impact factors is 
Table 2. Amino acid compositions of acid-soluble collagen (ASC) and pepsin-soluble collagen (PSC) (residues/1000 residues).

\begin{tabular}{|c|c|c|c|}
\hline Amino acid & ASC & PSC & $\begin{array}{c}\text { Type - collagen } \\
\text { (snakehead } \\
\text { scales) }\end{array}$ \\
\hline $\begin{array}{c}\text { Asparagine/aspartic acid } \\
\text { (Asp) }\end{array}$ & 44 & 43 & 41 \\
\hline Threonine (Thr) & 23 & 23 & 25 \\
\hline Serine (Ser) & 32 & 32 & 36 \\
\hline $\begin{array}{l}\text { Glutamine/glutamic acid } \\
\text { (Glu) }\end{array}$ & 66 & 66 & 75 \\
\hline Glycine (Gly) & 341 & 344 & 327 \\
\hline Alanine (Ala) & 123 & 123 & 127 \\
\hline Cystine (Cys) & 0 & 0 & 0 \\
\hline Valine (Val) & 17 & 17 & 26 \\
\hline Methionine (Met) & 14 & 14 & 13 \\
\hline Isoleucine (Ile) & 11 & 10 & 12 \\
\hline Leucine (Leu) & 22 & 21 & 20 \\
\hline Tyrosine (Tyr) & 4 & 3 & 1 \\
\hline Phenylalanine (Phe) & 14 & 13 & 16 \\
\hline Lysine (Lys) & 26 & 26 & 27 \\
\hline Histidine (His) & 5 & 5 & 7 \\
\hline Arginine (Arg) & 51 & 51 & 49 \\
\hline Proline (Pro) & 119 & 119 & 117 \\
\hline Hydroxyproline (Hyp) & 81 & 83 & 76 \\
\hline Hydroxylysine (Hyl) & 7 & 7 & 8 \\
\hline Total & 1000 & 1000 & 1000 \\
\hline
\end{tabular}

$\mathrm{B}>\mathrm{C}>\mathrm{A}$. Therefore, the optimal extraction process for enzymatic extraction of the scale collagen is $\mathrm{A} 2 \mathrm{~B} 3 \mathrm{C} 2$, namely, the enzyme amount is $4 \%$, the extraction time is $60 \mathrm{~h}$ and the solid-liquid ratio is 1:25. Under optimal conditions, the extraction rate of PSC is $12.06 \%$, so the extraction rate of the scale collagen is $17.15 \%$, which is significantly higher than that of the single acidic extraction or enzymatic extraction. The difference in the yields of ASC and PSC is due to many inter chain and intra chain crosslinks at the telopeptide region of the collagen, decreasing its solubile nature in acidic condition [19]. Further, in enzymatic extraction, the swelling mechanism of the scales in acidic solution makes pepsin cleave the cross-linked molecules easily at the telopeptide region without affecting the integrity of triple helical structure, resulting in a yield of PSC more than ASC [20-21].

\section{Protein Patterns}

Protein patterns of the ASC and PSC are presented in Fig. 2. Both collagens are composed of $\alpha_{1}$ and $\alpha_{2}$

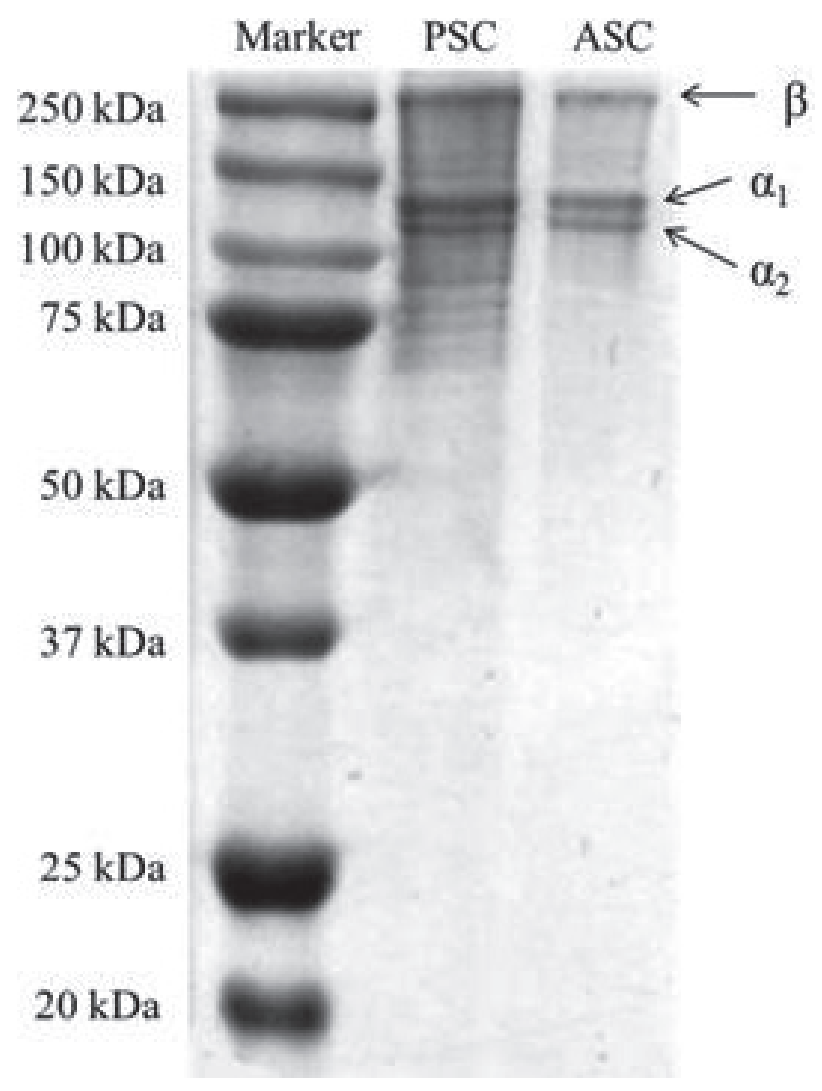

Fig. 2. SDS-PAGE of acid-soluble collagen (ASC) and pepsinsoluble collagen (PSC).

chains, indicating that collagen from silver carp scales belong to type I. The type I collagen consists of two identical $\alpha_{1}$ chains and one $\alpha_{2}$ chain (Ali et al., 2018). Molecular weight of $\beta, \alpha_{1}$ and $\alpha_{2}$ chains of ASC are about $268.7 \mathrm{kDa}, 145.9 \mathrm{kDa}$ and $124.4 \mathrm{kDa}$, respectively. And for PSC they are about $241.6 \mathrm{kDa}, 142.1 \mathrm{kDa}$ and $121.2 \mathrm{kDa}$, respectively. Both $\alpha_{1}$ and $\alpha_{2}$ chains of PSC have slightly lower molecular weights compared with those of ASC. This is due to the possibility of cleaving the peptides localized at the telopeptide region, and some small part of peptide was removed, leading the molecular of PSC to be smaller than ASC. This result is in agreement with Nalinanon et al. (2010), who found that $\alpha_{1}$ and $\alpha_{2}$ chains of PSC from the skin of arabesque greenling had slightly lower molecular weight than that of ASC.

\section{Amino Acid Composition}

The amino acid composition of ASC and PSC, expressed as residues per 1000 total residues, are given in Table 2. Both compositions of ASC and PSC are similar to type I collagen from snakehead scales. Gly is the most abundant amino acid and the amount is up to 341 residues per 1000 residues approximately, implying that the existence of $(\mathrm{Gly}-\mathrm{X}-\mathrm{Y})_{\mathrm{n}}$, triple helical repeat. The proline content of ASC and PSC are both 120 residues, suggesting that the structure of 
(Gly-Pro-Y $)_{n}$ accounts for about 35\% in the (Gly-X-Y) $)_{n}$. The amino acid of hydroxyproline is found in the structure, which is a peculiar amino acid of collagen. In general, the amino acid composition of ASC and PSC coincide with type I collagen.

\section{FT-IR Spectroscopy}

The FT-IR spectrum of both ASC and PSC of the scales is shown in Fig. 3, and corresponding characteristic absorption peaks of amides $\mathrm{A}$ and $\mathrm{B}$ as well as amides I, II and III are identified [24]. There are similar absorption peaks between ASC and PSC. A free $\mathrm{N}-\mathrm{H}$ stretching vibration occurs in the range of $3400-3440 \mathrm{~cm}^{-1}$, but amide A band of ASC and PSC are found at 3333 and $3335 \mathrm{~cm}^{-1}$, respectively, suggesting that the $\mathrm{NH}$ group is coupled with a hydrogen bond. Amide B peaks of ASC and PSC are found at $3082 \mathrm{~cm}^{-1}$, representing an asymmetrical stretch of $\mathrm{CH}_{2}$. The major feature of the IR spectrum of collagen is the amide I band absorption in the range of $1640-1660 \mathrm{~cm}^{-1}$, arising from the stretching vibration of $\mathrm{C}=\mathrm{O}$ groups along the polypeptide backbone, which is the sensitive marker of the peptide's secondary structure [25]. The amide I band of ASC and PSC was found in the absorption range at about $1659 \mathrm{~cm}^{-1}$. Furthermore, the amide II band, associated with $\mathrm{N}-\mathrm{H}$ bending vibration coupled with a C-N stretching vibration, which normally occurs at $1550 \mathrm{~cm}^{-1}$ and shifted to lower frequencies, suggesting the existence of hydrogen bonds in each collagen. The characteristic absorption peaks of amide III of ASC and PSC are found at about $1239 \mathrm{~cm}^{-1}$. The intensity ratio between amide III band and $1450 \mathrm{~cm}^{-1}$ band are approximately 1.10 and 1.12 for ASC and PSC, which thereby confirms the triple helical structure of the collagen [26]. The FTIR spectra reflected that both ASC and PSC were most likely in native triple helical

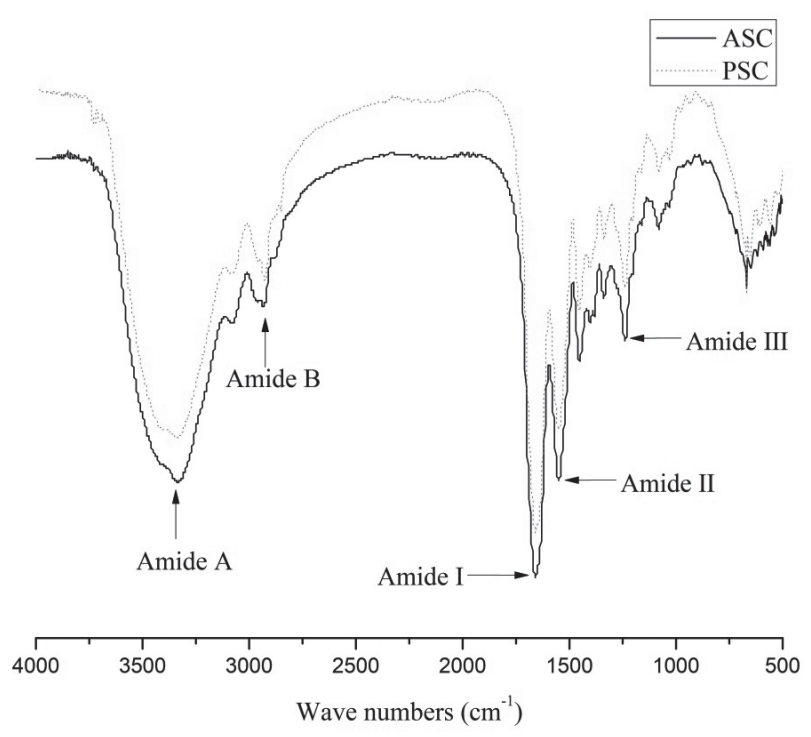

Fig. 3. FT-IR spectra of acid-soluble collagen (ASC) and pepsinsoluble collagen (PSC). conformation. Nevertheless, some differences in interand intra-molecular interactions existed between both collagens.

\section{Spectroscopy}

Fig. 4 shows CD spectrum of the ASC and PSC in the range of 190-260 $\mathrm{nm}$. CD spectroscopy is generally used to investigate the secondary structure of proteins. Native collagen is an optically active protein, which has triple helical conformation with a negative peak at 196-198 nm and a positive peak at $200 \mathrm{~nm}$ [27]. The CD spectra of ASC and PSC are almost the same, with a rotatory maximum at $220 \mathrm{~nm}$ and a negative peak at $197 \mathrm{~nm}$, so they are the typical spectrum of the collagen triple-helix structure. Once the collagen complete denaturation occurred, the positive peak of collagen at $220 \mathrm{~nm}$ disappeared completely and had a red shift of the negative peak. The peaks of ASC and PSC at $197 \mathrm{~nm}$ and $220 \mathrm{~nm}$ neither shifted nor disappeared, so the structure of ASC and PSC was not destroyed and kept a natural triple helical structure.

\section{Denaturation Temperature}

The thermal denaturation temperature of collagen is likely to affect the stability of collagen and could provide useful clues to the existence of collagen triplehelix. Fig. 5 shows that the transition temperature of ASC and PSC are about $34.26^{\circ} \mathrm{C}$ and $34.47^{\circ} \mathrm{C}$, respectively, corresponding to their triple helix changed from stretch to random coli, further indicating the existence of the triple helix of ASC and PSC. Imino acid (hydroxyproline and proline) plays a substantial role in the stabilization of triple helix due to the non-covalent bonding of their pyrrolidine ring [28], thus further affecting its denaturation temperature. The imino acid contents of ASC and PSC are 201 and 203 residues (Table 2), respectively; meanwhile, the Hyp/Pro of ASC and PSC are 0.67 and 0.70 , further indicating that the

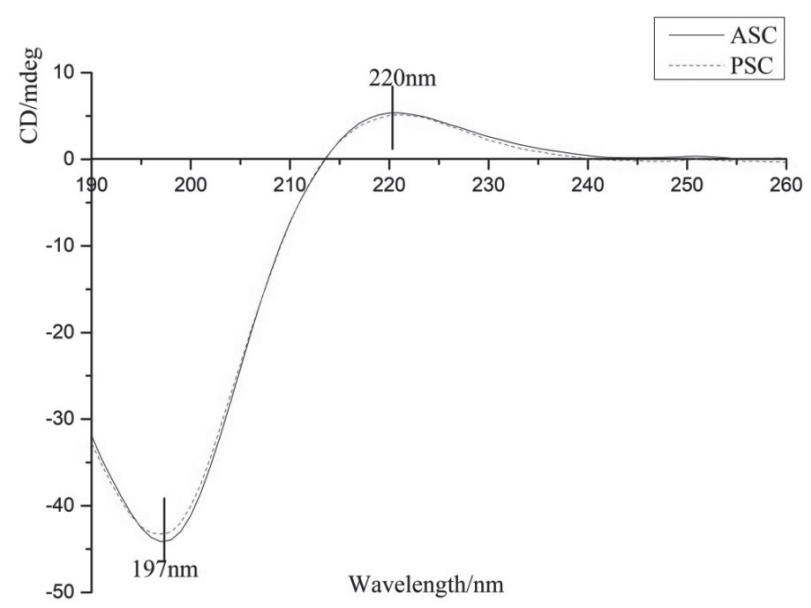

Fig. 4. CD spectra of acid-soluble collagen (ASC) and pepsinsoluble collagen (PSC). 


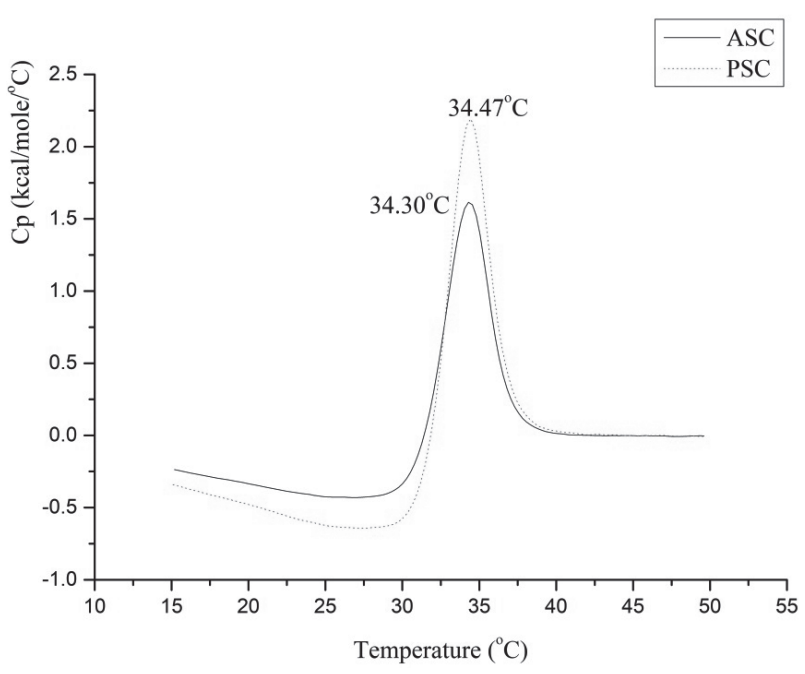

Fig. 5. US-DSC thermograms of acid-soluble collagen (ASC) and pepsin-soluble collagen (PSC)

stability of ASC is slightly lower than PSC, which is in accordance with the results in their thermal denaturation temperature.

\section{Conclusions}

In the present study, ASC and PSC were extracted from silver carp scales with a new acid-enzyme combined method. The yields of ASC and PSC were $5.09 \%$ and $12.06 \%$, respectively. Amino acid analysis indicates that the collagen contained about $34 \%$ glycine as the most abundant amino acid, and the contents of imino acids were both about $20 \%$. Similar SDS-PAGE profiles were found to be composed of $\alpha_{1}, \alpha_{2}$ and $\beta$. FT-IR spectra indicated that ASC and PSC were similar to typical type I collagen. ASC and PSC maintained their triple helical structures well. The denaturation temperatures of the ASC and PSC were $34.26^{\circ} \mathrm{C}$ and $34.47^{\circ} \mathrm{C}$, respectively. From these results, it is clear that ASC and PSC were type I collagen. Also, the yield of collagen was much higher than the reported, so silver carp scales have the potential to be an alternative source of collagen. Furthermore, the collagen information of silver carp scales obtained in the study may provide a theoretical foundation for the development of the fishery processing wastes related to reusing technology to reduce environmental pollution.

\section{Acknowledgements}

The authors wish to thank the Ministry of Science and Technology of China for the project of Co-operation in Science and Technology between Ukraine and China (item No. CU-01-10) and the National Natural Science Foundation of China (No. 21576171) for financial support.

\section{Conflict of Interest}

The authors declare no conflict of interest.

\section{References}

1. KITTIPHATTANABAWON P., BENJAKUL S., VISESSANGUAN W., NAGAI T., TANAKA M. Characterisation of acid-soluble collagen from skin and bone of bigeye snapper (Priacanthus tayenus). Food Chem. 89 (3), 363, 2005.

2. SINTHUSAMRAN S., BENJAKUL S., KISHIMURA H. Comparative study on molecular characteristics of acid soluble collagens from skin and swim bladder of seabass (Lates calcarifer). Food Chem. 138 (4), 2435, 2013.

3. ADDAD S., EXPOSITO J.Y., FAYE C., RICARD-BLUM S., LETHIAS C. Isolation, Characterization and biological evaluation of jellyfish collagen for use in biomedical applications. Marine Drugs. 9 (6), 967, 2011.

4. NAGAI T., ARAKI Y., SUZUKI N. Collagen of the skin of ocellate puffer fish (Takifugu rubripes). Food Chem. $\mathbf{7 8}$ (2), 173, 2002.

5. CERVERA M.A.R., VENEGAS E., BUENO R.P.R., MEDINA M.D.S., GUERRERO J.L.G. Docosahexaenoic acid purification from fish processing industry by-products. European Journal of Lipid Science and Technology. 117 (5), 724, 2015.

6. DEBIPERSADH S., SELVARAJAN R., SIBANDA T., NAIDOO R. Assessing toxic elemental concentrations in marine fish trachurus capensis (cape horse mackerel) and implications for public health. Pol. J. Environ. Stud. 27 (3), 1395, 2018.

7. DUAN R., ZHANG J.J., DU X.Q. Properties of collagen from skin, scale and bone of carp (Cyprinus carpio). Food Chem. 112 (3), 702, 2009.

8. LI C.M., ZHONG Z.H., WAN Q.H. Preparation and thermal stability of collagen from scales of grass carp (Ctenopharyngodon idellus). Eur Food Res and Technol. 227 (5), 1467, 2008.

9. MAHBOOB, S. Isolation and characterization of collagen from fish waste material- skin, scales and fins of Catla catla and Cirrhinus mrigala. Journal of Food Science and Technology-Mysore. 52 (7), 4305. 2015

10. WANG L.Z., YANG B., WANG R., DU X.Q. Extraction of pepsin-soluble collagen from grass carp (Ctenopharyngodon idella) skin using an artificial neural network. Food Chem. 111 (3), 683, 2008.

11. ZHANG J.J., DUAN R., YE C., KONNO K. Isolation and characterization of collagens from scale of silver carp (Hypophthalmichthys molitrix). J. Food Biochem. 34 (6), 1343, 2010.

12. AOAC. Official methods for analysis. Association of official analytical chemist Inc, Arlington, 2000.

13. AKAGUNDUZ Y., MOSQUERA M., GIMENEZ B., ALEMAN A., MONTERO P., GOMEZ-GUILLEN M.C. Sea bream bones and scales as a source of gelatin and ACE inhibitory peptides. LWT-Food Science and Technology. 55 (2), 579, 2014.

14. WU Q.Q., LI T., WANG B., DING G.F. Preparation and characterization of acid and pepsin-soluble collagens from scales of croceine and redlip croakers. Food Science and Biotechnology. 24 (6), 2003, 2015.

15. WU J.C., GAO Y.P., ZHANG J.W., WANG Y., CHEN W.Y. chrome complexes in rewetting and neutralizing effluents 
and hints for recycling post-tanning wet-process effluent. Pol. J. Environ. Stud. 27 (3), 1, 2018.

16. SARKAR H.S., DAS S., RISSANEN K., SAHOO P. First chemosensor for selective detection and quantification of 1-4-hydroxyproline in collagen and other bio samples. Analytical Chemistry. 89 (24), 13054, 2017.

17. SHAMANSKY L.M., PRATT D., BOISVENUE R.J., COX G.N. Cuticle collagen genes of haemonchus-contortus and caenorhabditis-elegans are highly conserved. Molecular and Biochemical Parasitology. 37 (1), 73, 1989.

18. HONG H., ROY B.C., CHALAMAIAH M., BRUCE H.L., WU J.P. Pretreatment with formic acid enhances the production of small peptides from highly cross-linked collagen of spent hens. Food Chem. 258, 174, 2018.

19. ISWARIYA S., VELSWAMY P., UMA T.S. Isolation and characterization of biocompatible collagen from the skin of puffer fish (Lagocephalus inermis). Journal of Polymers and the Environment. 26 (5), 2086, 2018.

20. VEERURAJ A., ARUMUGAM M., AJITHKUMAR T., BALASUBRAMANIAN T. Isolation and characterization of collagen from the outer skin of squid (Doryteuthis singhalensis). Food Hydrocolloids. 43, 708, 2015.

21. WANG Z.B., WANG L., LIN S.M., LIANG Q.F., SHI Z.J., XU J.M., MA H.L. Isolation and characterization of collagen from the muscle of Amur sturgeon (Acipenser schrenckii). Biotechnology and Bioprocess Engineering. 19 (5), 935, 2014.

22. ALI M.M., BENJAKUL S., PRODPRAN T., KISHIMURA $H$. Extraction and characterisation of collagen from the skin of golden carp (Probarbus jullieni), a processing byproduct. Waste and Biomass Valorization. 9 (5), 783, 2018.
23. NALINANON S., BENJAKUL S., KISHIMURA H. Collagens from the skin of arabesque greenling (Pleurogrammus azonus) solubilised with the aid of acetic acid and pepsin from albacore tuna (Thunnus alalunga) stomach. J. Sci Food Agr. 90 (9), 1492, 2010.

24. LEE J.K., KANG S.I., KIM Y.J., KIM M.J., HEU M.S., CHOI B.D., KIM J.S. Comparison of collagen characteristics of sea- and freshwater-rainbow trout skin. Food Science and Biotechnology. 25 (1), 131, 2016.

25. PUTTAWIBUL P., BENJAKUL S., MEESANE J. Preparation and Characterization of an In Situ Hydrogel of selfassembly Type I Collagen from Shark Skin / methylcellulose for Central Nerve System Regeneration. Journal of Biomimetics Biomaterials and Biomedical Engineering. 24, 14, 2015.

26. KAEWDANG O., BENJAKUL S., PRODPRAN T., KAEWMANEE T., KISHIMURA $\mathrm{H}$. Characteristics of gelatin extracted from the swim bladder of yellowfin tuna (thunnus albacores) as affected by alkaline pretreatments. Journal of Aquatic Food Product Technology. 25 (8), 1190, 2016.

27. WEGENER H., PAULSEN H., SEEGER K. The cysteinerich region of type vii collagen is a cystine knot with a new topology*. Journal of Biological Chemistry. 289 (8), 4861, 2014.

28. MOTOOKA D., KAWAHARA K., NAKAMURA S., DOI M., NISHI Y., NISHIUCHI Y., KANG Y.K., NAKAZAWA T., UCHIYAMA S., YOSHIDA T., OHKUBO T., KOBAYASHI Y. The triple helical structure and stability of collagen model peptide with 4(s)-hydroxyprolyl-pro-gly units. Biopolymers. 98 (2), 111, 2012. 